\title{
DESIGNING AN EFFECTIVE KNOWLEDGE MANAGEMENT SCRIPT MODEL WITH THE IT APPROACH
}

\author{
Javad Moghtader Kargaran ${ }^{1}$ \\ Reza Khodaei Mahmudi²
}

\begin{abstract}
Knowledge management strategy identifies a pathway to the goals of the organization, whose main purpose is to actualize knowledge management in an organization. Knowledge
\end{abstract} management should serve the strategic orientation of the organization and its strategic interaction with the turbulent and changing environment of the business. Knowledge and management alone and independently from the strategic goals of the organization is meaningless and worthless. Therefore, knowledge management organization should be consistent and coordinated with the organization's strategic actions at the macro level. The aim of this research is to provide an effective knowledge management model with The strategic approach is in the military organization. The research method of this study was applied in a descriptive, surveyed manner based on the descriptive information gathering method. To collect data, a questionnaire was used. The initial data of the research using semi-open and Delphi interviews were collected from the college knowledge college of knowledge management and analyzed using Micmac software. Finally, the results of using the cross-impact analysis method indicated that the six key factors identified by the six factors identified in the interview phase had the greatest impact on the future of the Military Knowledge Foundation has it These factors were used as the main factors in scenario, at first three scenarios were raised. The first scenario was related to the goal scenario, the second scenario was related to knowledge and the third resource of human resources. The first scenario was the best with optimal planning. Then, each of the key components was ranked. The results of

\footnotetext{
${ }^{1}$ Department of Governmental Management, Tabriz Branch, Islamic Azad University, Tabriz, Iran.

2 Department of Management, Tabriz Branch, Islamic Azad University, Tabriz, Iran. Corresponding Author Email: Reza_khodaie43@yahoo.com
} 
the research showed six main factors of planning, specialized knowledge, strategy, information, team spirit and experts as components of effective knowledge management model with a strategic approach in the organization.

Keywords: Knowledge Management, Information Technology

\section{Introduction}

Nowadays, knowledge has become one of the driving forces for success in business. Instead of physical force, it is spent on the power of mind and mind. The advent of the revolution in information technology, the formation of the information and networking society as well as the growth and The rapid development of superior technology, especially in the field of communication, computer and engineering, has changed since the 1990s the pattern of global economic growth. As a result of these developments, knowledge as the most important capital has replaced financial and physical capital in the global economy. As knowledge is considered to be the most strategic source of enterprise, organizations are faced with the fundamental question of how to manage organizational knowledge efficiently and effectively in order to benefit from its benefits to the strategic goals of the organization. In this way, the establishment of an efficient and effective knowledge management system as a key competence of organizations in the new era, which can provide sustainable competitive advantage, is posed. A very significant point that leads to a strategic approach to knowledge management is that knowledge management should serve the strategic orientation of the organization and its strategic interaction with the turbulent and changing environment of the business. Knowledge and management of it is individually and independently of the strategic goals of the organization is meaningless and worthless. Therefore, knowledge management organization should be consistent with and consistent with the organization's strategic actions at the macro level. On the other hand, more productivity than human capital, more efficient and effective learning of human resources, more value added goods and services, employee satisfaction are all of the objectives of knowledge management in an organization. Knowledge management in 
organizations is considered as a process in which an organization generates wealth from its knowledge or intellectual capital and, by designing appropriate patterns, prevents the loss of national capital.

\section{The Influence of Information Technology on Knowledge Management}

Information technology is one of the most effective factors for implementation of knowledge management in organization. To implement knowledge management, there are various tools and techniques that are supported by information technology. Knowledge management uses information technology as a powerful tool to improve its processes. Information technology can integrate dispersed knowledge into the organization and, in the shortest possible time, carry out the most activities for the transfer of information.

Knowledge management and information technology are interconnected because they both contribute to the dissemination of knowledge vertically and horizontally in the organization, and make it easier to use and search knowledge in the organization. The goal of many organizations is to use advanced information technology to manage knowledge management in the organization. In fact, there is a strong and consistent relationship between knowledge management and information technology. For example, most organizations regard the acquisition of knowledge about the needs of their customers and their clients, and they want to increase their knowledge Develop new products and services about customers. Traditional views, such as customer questionnaires, do not say much about customer-specific needs to organizations, because customers do not exactly know what they want. By developing effective market research systems and analyzing customer preferences, organizations can well identify the real needs of their customers and their clients. All of this is possible with the help of information technology. Business expert systems, customer relationship management, and data mining are a few examples of IT applications for knowledge management, in order to increase their knowledge of their customers.

Lin and T. Stone (2005) also argue that organizations should have 
advanced information technology systems to facilitate the use of knowledge in the organization. Davenport (1998) also believes that the creation of knowledge management based on the IT infrastructure in an environmental organization, in which knowledge is easily shared across the organization.

\section{Information Technology 4} plays a different role in knowledge management:

1. Knowledge acquisition;

2. Defining, storing, classifying, indexing and connecting knowledge-based components;

3. Search and identify related concepts;

4. Flexible expression of concepts based on various applied fields

Using information technology in knowledge management processes can reduce the cost of using information and increase the speed of knowledge flow. Therefore, information technology is a key tool for the management of Astma's knowledge. It should always be remembered that information technology is the only communication path and system for storing information for the exchange of knowledge. This technology can not be a maker or a creator of knowledge. For example, in an organization with a knowledge-based culture, it does not guarantee the use of information technology, knowledge production or its promotion, and does not transform the culture of knowledge hoarding into a culture of knowledge sharing (Davenport, 2000).

\section{Prospective Knowledge Management}

Future organizations are an information-based enterprise or information organization. Knowledge management is the process of identifying smart assets and creating a culture and information infrastructure that encourages participation and learning. This process seeks for intelligent capital through the acquisition, rearing and use of all that the employees know. It creates capital in collective organizations, which add value through its transfer to new products and services. Davenport and Prozac believe that knowledge management is the exploitation and development of the knowledge capital of an organization to achieve the goals of the organization.

KM helps people in the organization communicate and share their knowledge. This ensures the organization's success in competition 
among other organizations. The implementation of knowledge management in an organization leads to the knowledge generated by individuals to remain forever in the organization, and as a result of staff withdrawal from the organization, the knowledge generated does not go out of the organization according to the cost that the organization has just spent on its production. The purpose of knowledge management Identify, collect, categorize and organize, store, share, distribute and make available knowledge at the organization level. The implementation of knowledge management in the organization leads to the knowledge produced by individuals to remain for the organization at all times, and as a result of the withdrawal of employees from the organization, the knowledge produced does not go away from the organization with due regard to the cost that the organization merely makes for its production. The purpose of $\mathrm{KM}$ is to identify, collect, categorize and organize, store, share, distribute and make available knowledge at the organization level. The main elements of the knowledge management cycle are production, organization, storage, sharing and use. Knowledge is derived from a variety of ways, either through people who have knowledge or through various journals, conferences, meetings, reporting, holding training sessions and workshops, organizing exhibitions, etc., The useful knowledge gained inside or outside the organization is identified and collected, then organized and organized according to a specific order. Organized knowledge can be stored and maintained in a variety of ways in files, databases, libraries, and more.

Internal and external studies on the implementation of knowledge management

The implementation of knowledge management in an organization leads to the knowledge generated by individuals to remain forever in the organization, and as a result of staff withdrawal from the organization, the knowledge generated does not go out of the organization according to the cost that the organization has just spent on its production. The purpose of knowledge management Identifying, collecting, categorizing and organizing, storing, sharing, disseminating and making knowledge available at the organization level. In organizations that are 
traditionally managed, knowledge goes from top to bottom across organizational lines. In this case, knowledge is rarely available at the right time and where it is most needed. But in knowledge-based organizations that implement and implement knowledge management, knowledge flows throughout the organization, and anyone who needs it at the right time can use it to carry out their duties. The implementation of knowledge management in the organization leads to the knowledge produced by individuals to remain for the organization at all times, and as a result of the withdrawal of employees from the organization, the knowledge produced does not go away from the organization with due regard to the cost that the organization merely makes for its production. The strategic management approach emphasizes the interaction of managers at all levels of the organization and business and brings specific behavioral outcomes that are characteristic of the participatory decision-making system, therefore, the study of the accurate diagnosis and evaluation of the effect of formulating the strategy on the performance of the organization or acquisition And work often requires a set of financial criteria
272

and so on that evaluates the effectiveness of managers. Yanche et al. (2015) explored how and why information systems increase the company's performance from a knowledge management perspective. By developing a knowledge management perspective and organizational learning theories, they developed and tested an empirical model in which knowledge sharing interacted with the information systems and performance of the company. The results suggest that supporting the research model and confirming that information systems have a positive impact on corporate performance and knowledge sharing as a mediator on information systems. Study Rich, Gemini, and Saur (2013) examines the relationship between knowledge management and various aspects of performance in business-activated business projects with information technology. The proposed theory assumes that knowledge management is a tool for project performance when it is affected by a new concept, the knowledge balance. Their research findings show that project managers who have achieved knowledge balancing between people and the artifacts of the three project sectors - the IT team, the 
business change team, and the leadership team - can have a significant positive impact to achieve the business value of the project. Results show that achieving higher levels of knowledge does not have a significant negative impact on the achievement of program and budget goals. This is the first statistical study to demonstrate the effect of knowledge management and knowledge levels on achieving project management goals and business value in IT-enabled projects. Mansor elkour and colleagues (1394), "The Relationship between Knowledge Management and Organizational Innovation (Case Study: General Office of Shipping and Marine Affairs of Mazandaran Province)". Inferential Findings showed that knowledge management components had significant predictive value of organizational innovation variable. And also the results of Mobin Ayn's structural model, which explains the variable of knowledge management of $62 \%$ of the innovation variable. (Mansoorlkour, Soltani Lerkani and Godfather, 1394). Salehi and Ziglari (1394) investigated the relationship between organizational structure and knowledge management components in Ahwaz city water and wastewater organization. The results of this study
273

indicated that the specialization of tasks and the assignment of each job to a specialist led to improvement of the process of knowledge management, which is justified by the nature of the organization that serves as a service (Salehi Viziglari, 1394)

\section{Research questions}

1. What are the key drivers of change in effective knowledge management with the IT approach in the military?

2. What are the alternative scenarios for effective knowledge management with the IT approach in the military? Tools and research methods

Our research is based on the purpose of applied research, and based on the nature and method of our research, we have a field survey. In general, we use a scientific research, a descriptive survey to design a model for effective knowledge management with a strategic approach in the military organization, military organization using a compilation scenario. Peter Schwartz, 1996, in the book "Art of Persuasion" describes the scenario-based planning steps as follows:

Step 1: Understanding the issue and the main decision 
Step Two: List of Key Factors

on the Development of Regions

Step 3: Identify Key Drivers

Step Four: Classification Based

on Importance and Uncertainty

Step Five: Identify critical uncertainties

Step Six: Developing scenarios

Step 7: Analyze the outcomes and outcomes of each scenario

Step 8: Select Strategic Indicators

In this study, these steps have been used.

Foresight is a concept that has emerged from the inability of predictive knowledge, policy knowledge and strategic management knowledge to respond to specific challenges (Nazemi and Ghadiri, 2006). It is predicted in the future, but in future writing, the future is constructed (Mozaffari,.

Prophecy is the manifestation of man's will and authority in the future architecture that follows a normative model, in which, planning firstly goes to the future of the desirable horizons and attends and observes And past, the path Determining and Determining a Specific Architecture for the Development Architecture of the Future (Bilali,.) 1391 The Importance of Forecasting in the
Strategic Field is to a degree that Peter Slater, the founder of the Australian Center for Future Studies and SecretaryGeneral of the World Wide Web, has always Combining strategic forecasting (Shahjerdi,. (2012). Forecasting is a systematic effort to examine the longterm future of science, technology, economics, environment and society to identify emerging generic technologies as well as the field. Underlying strategic research that may have the most economic and social benefits (Ahmadi and Ghazi Noori, 2003).

The statistical population of this research is 1000 official and professional staffs with a bachelor's degree and above the military organization. In this research, we use randomized stratified sampling.

The Cochran formula was used to obtain sample size. The sample size was 277 . This calculation is made with a $5 \%$ error rate.

One of the most important parts of each research work is data collection. If this is done in a regular and correct manner, the analysis and conclusion of the data will be done with great speed and accuracy. Methods of data collection are divided into two groups of library and field. Regarding 
the collection of information about the subject literature and the history of the research, library methods are used and the field method is used to collect information to confirm or reject the research hypotheses.In this research, the following methods are used to collect the information and data needed to examine the questions raised.

\section{1- Library method and search of} web networks (Internet-Extranet-local network) to get more familiar with research topic and study of studies done in this field.
275

2. Field method using questionnaire preparation and distribution.

\section{Variables and Indicators}

In the first stage, using the theoretical framework, three fields of objectives, knowledge, and human resources were identified. Then, using semi-open interviews with 7 experts, 6 factors from these three areas were identified on the future of the military organization of knowledge base, which are listed in the table below:

\begin{tabular}{|l|l|l|l|l|l|}
\hline Factor & Background & Factor & Background & Factor & Background \\
\hline specialist & $\begin{array}{l}\text { Human } \\
\text { resource }\end{array}$ & $\begin{array}{l}\text { Updated } \\
\text { information }\end{array}$ & knowledge & Planning & target \\
\hline $\begin{array}{l}\text { Teamwork } \\
\text { spirit }\end{array}$ & & $\begin{array}{l}\text { Professional } \\
\text { knowledge }\end{array}$ & & $\begin{array}{l}\text { Determine } \\
\text { the strategy }\end{array}$ & \\
& & & & & \\
\hline
\end{tabular}

In the second step, six factors identified in the cross-effects matrix were analyzed by MicMac software. The MicMac software is designed to perform complex calculations of the crosssectional matrix. The method of this software is to first identify the important variables and components in the domain and then identify them in a matrix such 
as the impact analysis matrix and the extent of the relationship between these variables with the domain concerned by the experts. The variables in the rows are influenced by the column variables (Zali, 2009). Figure 1 shows the position of effective and influential variables in a two-dimensional graph. Strategic variables are variables that can be manipulated and controlled, and affect the dynamics and system change. By describing variables that have a high impact but cannot be controlled, it cannot be considered as a strategic variable. Assuming the state diagram of the variables as a coordinate grid, the variables in zone 2 have such a state.
Planners are rarely able to change these variables. The variables located in area 3 of the network have very low impact and very low impact and cannot be considered a strategic change. Region 4 variables are not strategic because of their strong dependence on other variables, and are mostly due to other variables. But variables in Region 1 are strategic variables, because they are also manageable by the management system. As well as the system's impressive impact. In fact, the closer the end of region 3 to the end of area 1 of the coordinate network, the magnitude of the importance of the variable is increased (Rabbani, 1392)

\section{Two-way Variables}

Effective strategic variâbles

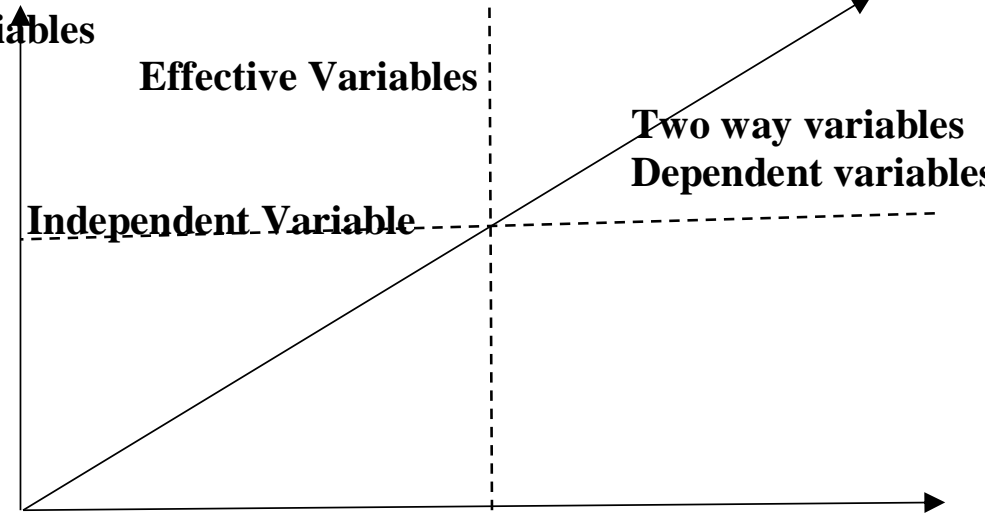

and

Figure 1 - the position of strategic variables (Rabbani 1391) 
Since 6 key variables were identified, the dimensions of the $6 \times 6$ cross-impact matrix were set in three different sections. The maturity rate is $32 \%$, which indicates that the selected factors have not had a large and dispersed impact on each other, and in fact the system has been stable. The relation to be evaluated in this matrix is the ratio of zero, which means that the factors do not affect each other or have not been influenced by each other. The matrix is based on statistical indices with two-fold data rotation of desirability and optimization of $100 \%$ which indicates the high validity of the questionnaire and its responses. The output of the Micmac software identified six factors among the six identified factors as the final key factors. The six factors in Figure 1 in Area 1 of Coordinate 2 are indicative of the key variables that shape the future of the knowledge based organization with the IT approach and ranking. These factors were used as the main factors in the scenario.

Table3_status 3 key factor affecting the process of military organizations knowledge base with the IT approach

\begin{tabular}{|l|l|l|}
\hline condition & subset & Factors \\
\hline A1 & Planning & Targets \\
\hline A2 & strategy & Targets \\
\hline B1 & Updated information & Knowledge \\
\hline B2 & Professional knowledge & Knowledge \\
\hline C1 & Specialists & Human resource \\
\hline C2 & Team work spirit & Human resource \\
\hline
\end{tabular}

\section{Prospects and scenarios}

In the third stage, scenarios were developed using the basics and Scenario wizard software. The Scenario wizard software is designed to perform complex scenario computations. After selecting key factors, each factor is classified into different situations and these conditions are provided to development experts for all key factors in a matrix. In this questionnaire, the situation can also show a negative effect, and the numbers of the questionnaire vary from 3 to 3 . The purpose of this software is to optimize the scenarios and reassure them. Table 3 describes the key effective factors and the subset status of each agent.

In outline scenarios and scenarios, three possible future levels, 
believable futures and possible future are evaluated (Godet, 2008)

Possible Futures: Includes all possible situations that can be realized in the future. This spectrum of futures is a collection of images that human beings consider for their future, and are mostly imaginative and the result of the depiction of the human mind. These futures are beyond today's human knowledge and knowledge.

Believable Futures: Includes things that, based on the present knowledge of mankind, are likely to emerge in the future, and contrary to the possible future, which is inconsistent with the current human knowledge and principles, these futures are in line with these principles. Believable future is a subset of possible futures.

Possible future prospects are likely to materialize. These futures are sub-collections of believable futures. In a scenario for the future, a combination of possible, probable and believable future is drawn up as a desirable future, and in order to achieve that, different scenarios, including contradictory, proportional, different and similar scenarios, are formulated (Verus , .2003) In assessing military organization scenarios, all six factors

\section{8}

were selected as the strongest scenario in knowledge management with a strategic approach.

Conclusion

and

\section{Recommendations}

Future organizations will be knowledgeable organizations, and generally include professionals who adjust their work paths and rules from the feeds received from colleagues, customers and their managers, and on this basis, the center of gravity of the use of the workforce from simple employees And physical changes to knowledge workers that will resist the behavioral approaches that the business environment has taken over a hundred years ago from military environments and will bring about a transformation in organizational activity (Drucker, 2007, 24 )

Knowledge gives power to the organizational structure, allowing members of the organization to show organizational values and capabilities in the specified way, this creates the opportunity for creativity and innovation within a kind of cultural context that leads to coherence. Knowledge ensures maximum employee independence, creative activity and the production of organizational wisdom, and ultimately 
develops the ability of self-management of individuals and groups. In the structure of knowledge organization, knowledge groups rather than managers of each sector as well as knowledge teams instead of supervisors are tasked with, and most importantly, the replacement of knowledge workers by the ordinary staff of the organization. The implementation of knowledge management in an organization leads to the knowledge generated by individuals to remain forever in the organization, and as a result of staff withdrawal from the organization, the knowledge generated does not go out of the organization according to the cost that the organization has just spent on its production. The purpose of knowledge management Identifying, collecting, categorizing and organizing, storing, sharing, disseminating and making knowledge available at the organization level. In organizations that are traditionally managed, knowledge goes from top to bottom across organizational lines. In this case, knowledge is rarely available at the right time and where it is most needed. But in knowledge-based organizations that implement and implement knowledge management, knowledge is current in the entire organization, and everyone can use it to do their jobs at the right time. This research is sought after. The purpose of this paper was to present an effective knowledge management model with a strategic approach in the organization. At first three scenarios were presented. The first scenario was related to the goal scenario, the second scenario for knowledge and the third scenario of human resources. The first scenario was the best with optimal planning. Subsequently, each of the key components was ranked. The results of the research showed that planning for the first rank, specialized knowledge, strategy determination, up-to-date information, team spirit and specialists ranked Are next. Based on the results, the following suggestions have been made for future research:

- Perform similar investigations in other public and private institutions.

- Presenting standards to provide an effective knowledge management model with a strategic approach

- Investigating the impact of information technology on the organization's strategic approach. 
- The Impact of Knowledge Management Process on Organizational Strategic Approach.

- Investigating the impact of organizational culture on the organization's strategic approach.

- Use of other methods of collecting information such as interviews.

Perform cross-sectional research and compare results at different times.

\section{Internal resources}

Azari, Mehrdad, 2002, Knowledge Management, Performance and Challenges, Tadbir Monthly P. 114-46.

Abtahi, Hossein, Salavati, Adel, 2006, Knowledge Management in Organization, Tehran, New Link Publishing.

August, Steven \& Schafferitz, Jay. M, 2000, Organizational Theories: Myths, Translation by Ali Parsaeean, Tehran: Afsharat Farzaneh, First Edition.

Parham, Shohreh (1389). Explaining the Challenges of Knowledge Management Implementation and Introducing an
Appropriate Model for Bidding at Shahid Chamran University of Technology. Associate Professor, Shahid Chamran University of Ahvaz. Hassanzadeh, Mohammad (2009).

Investigating the Infrastructural Factors of Knowledge Management in the Government of the Islamic Republic of Iran. . Daneshvar Journal of Behavior, 16 (25): 11-26.

Time, Bibi Eshrat (1386). The study of knowledge management infrastructures in the faculty of pedagogical and psychosocial sciences of the University of Isfahan from the point of view of faculty members and providing solutions to improve it. Retrieved on October 10, 2010 , from http://www.civilica.com/paper IKMC01.IKMC01_005.htm

Senge, Peter M., The fifth commandment. Translators: Hafez Kamal Hedayat and Mohammad Roshan. Tehran, Managing Director.

Fatollahi, Banafsheh; Ibrahim Afshar Zanjani; Damon Nozari. (1388). Feasibility study on knowledge management implementation in Isfahan 
University. Proceedings of Knowledge

Management and Information Science:

Links and Interviews by Mohammad

Nazadeh and others. Tehran, Library

Publisher.

Abbasi, Zohreh, A Review of Knowledge Management

Implementation Models in

Organizations (2007), First National Conference on Knowledge

Management, Tehran.

Maleki, Qasem, 2006, Providing a framework for moving information management from knowledge management to research and development organizations, master's thesis, Malek Ashtar University of Technology.

Mohammadi, Mohammad, 2000, What is your strategy for knowledge management, Sharia Tidbir No. 107.

Mousalis, Nikos, 1385, Organization and Bureaucracy: An Analysis of New Theories, Translated by Hasan Mirzaei Ahrendani and Ahmad Tedini, Tehran: Publishing \& Publishing Institute of Tehran University, First Edition
Hemmati, Mohammad (2010). Evaluation of the application of knowledge management components in Tehran Technical College. The paper presented at the first national conference of knowledge management in Tehran.

Chang, M.Y., Hung, Y.C., Yen, D.C. ND Tseng,P.T., 2009, "The research on the critical success factors of knowledge management and classification framework project in the Executive Yuan of Taiwan Government", Expert Systems with Applications,9(12), pp. 5376-5386.

Chen, C., 2004, "The effects of knowledge attribute, alliance characteristics, and absorptive capacity on knowledge transfer performance", $\mathrm{R} \& \mathrm{D}$

Chen, C.J. and Huang, J.W., 2007, "How organizational climate and structure affect knowledge management-The social interaction perspective", International Journal of Information Management,5(12), pp. 104-118.

Chen, J., Z. Zhu and H. Y. Xie (2004), Measuring intellectual capital: a new 


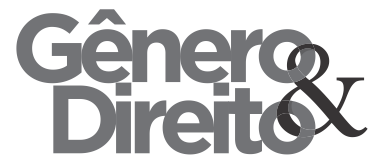

Periódico do Núcleo de Estudos e Pesquisas sobre Gênero e Direito

Centro de Ciências Jurídicas - Universidade Federal da Paraíba

V. 8 - No 03 - Ano 2019

ISSN | 2179-7137 | http://periodicos.ufpb.br/ojs2/index.php/ged/index model and empirical study, Journal of Intellectual Capital, 5(1): 195-212.

Depres, C. and Chauvel, D., 1999, "Mastering Information Management: Part Six-Knowledge Management", Financial Times, 14(2), pp. 4-6.

Drucker, P. (1992), Managing for the future: The 1990s and beyond, New York: Truman.

Donoghue, L. P., Harris,J. G., and Weitzman,A. B.(1999). Knowledge management strategies that create value. Outlook, 1: 48-53.

Glaser, R. (1998), Measuring the knower: toward a theory of knowledge equity, California Management Review, Vol. 40, No. 3, P: 175-194.

Hafez nia, Mohamad Reza (1998), Introduction on Research Method in Human Science ,Tehran ,samt publication.

Kinney, T., 1998, “Knowledge management,intellectual capital and adult learning", Adult Learning,4(1), pp. $2-5$.
282

Lucier, C., 2003, "When knowledge adds up to nothing: Why knowledge management fails and what you can do about it", Development and Learning in Organizations, 17(1), pp. 32-35.

Snowden, D, 2000, "Liberating knowledge",Liberating knowledge, 1(1), pp. 6-19.

Lee, Hawan -Jang; Young - Gul Kim. "A Stage Model of Organizational Knowledge Management: A Latent content Analysis". Expert Systems with Applications, 20, (2001), 299 - 311.

Nissen, M.E., 1999, "Knowledge-Based Knowledge Management in the Reengineering Domain”, Decision Support Systems, 27(1), pp. 47-65.

Nonaka, I., Takeuchi, H. (1995). The Knowledge Creating Company: How Japanese Companies Create the Dynamics of Innovation, Oxford University Press, New York, NY.

McAdam, Rodney; Sandra McCreedy. "A Critical Review of Knowledge Management models". The Learning Organization, vol, 6 (3), , (1999), 91100. 


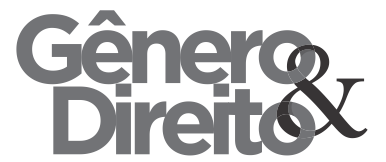

Periódico do Núcleo de Estudos e Pesquisas sobre Gênero e Direito

Centro de Ciências Jurídicas - Universidade Federal da Paraíba

V. 8 - No 03 - Ano 2019

ISSN | 2179-7137 | http://periodicos.ufpb.br/ojs2/index.php/ged/index
Plessis, M.d., 2008, "What bars organisations from managing knowledge successfully", International Journal of Information Management, 28(1), pp. 285- 292.

Price Water House Coopers, 1999, “Gartner Group's knowledge management glossary", Global Enterprise Advisor, 12(1), pp. 3-5.

TECTEM (2001), Benchmarking project knowledge management, Benchmarking Center, University St. Gallen, Switzerland, Screening Report: 37.

Toffler, A. (1990), Power shift: knowledge, wealth and violence at the Edge of the 21st century, New York: Bantam Books.

Vashishta, R., Kumar, R. ,and Chandra, A. (2010). Barriers and facilitators to knowledge management: evidances from selected Indian universities. The IUP Journal of Knowledge Management, 8 (4): 7-24.

Wong, K.Y., 2005, "Critical success factors for implementing knowledge management in small and medium enterprises", Industrial Management \& Data Systems, 105(3), pp. 261-279.

Zawawi, A. and et al. (2011). The study of barriers factors in knowledge sharing: A case study in public university. Management Science and Engineering, 5 (1): $59-70$ 